\title{
N-Terminal Pro-Brain Natriuretic Peptide: Prognostic Potential in End Stage Liver Cirrhosis in a Cohort Free of Heart Failure; an Egyptian Insight
}

\author{
Elham Ahmed Hassan ${ }^{1 *}$, Abeer Sharaf EL-Din Abd El-Rehim ${ }^{1}$, Zain EL-Abdeen Ahmed Sayed ${ }^{2}$, Heba Ahmed Abdelhafez ${ }^{3}$ and Muhamad \\ Ramadan Abdelhameed ${ }^{2}$
}

${ }^{1}$ Department of Tropical Medicine and Gastroenterology, Faculty of Medicine, Assiut University, Assiut, Egypt

${ }^{2}$ Department of Internal Medicine, Faculty of Medicine, Assiut University, Assiut, Egypt

${ }^{3}$ Department of Clinical Pathology, Faculty of Medicine, Assiut University, Assiut, Egypt

\begin{abstract}
Background: Natriuretic Peptide (NP) system has emerged as one of the most important hormonal systems in control of cardiovascular homeostasis. Liver cirrhosis may affect NP levels that were well described in heart failure. NP prognostic evaluation was well established in many diseases.

Objectives: to measure serum and ascitic NT-proBNP levels in cirrhotic and cardiac Egyptian patients to diagnose a cut-off value for exclusion of heart failure, to assess if cirrhosis per se may contribute in NT-proBNP elevation and to assess the contribution of these levels as predictors of mortality in liver cirrhosis.

Patients and methods: A prospective cohort study was conducted in 80 patients (50 cirrhotics and 30 had heart failure). Serum and ascitic (if available) NT-proBNP were measured. Cirrhotic patients were followed for 1-year. Kaplan-Meier survival analysis was used to evaluate 1-year survival rates. Logistic regression analyses were performed with 1-year mortality as the dependent variable.

Results: Median serum and ascitic NT-proBNP levels in cirrhotics were 239.4 and $267 \mathrm{pg} / \mathrm{ml}$ versus 10596.6 and $9771 \mathrm{pg} / \mathrm{ml}$ in heart failure patients $(P<0.001)$. Serum and ascitic NT-proBNP cut-off values $>1000 \mathrm{pg} / \mathrm{ml}$ resulted in sensitivity of $100 \%$ and $93.3 \%$ and specificity of $97.8 \%$ and $92.5 \%$ for exclusion of cardiac disease in cirrhotics. NT-proBNP was elevated in cirrhotics compared with age matched controls $(P<0.001)$ and significantly correlated with severity of liver cirrhosis based on Child-Pugh and MELD $(P=0.05, P<0.001$ respectively). Higher NT-proBNP associated with increased 1-year mortality. NT-proBNP was an independent predictor for mortality in cirrhotics in addition to other conventional factors.

Conclusion: NT-pro BNP could be a powerful initial non-invasive diagnostic tool for exclusion of heart disease in cirrhotic patients. End stage cirrhosis per se may contribute to NT-proBNP elevation. NT-proBNP provided incremental information in 1-year mortality prediction in decompensated cirrhotics.
\end{abstract}

Keywords: Liver cirrhosis; 1-Year mortality; NT-proBNP; Prognosis

\section{Introduction}

In last decades, there are improving efforts to understand cardiovascular changes in liver disease. Deterioration of liver function and portal hypertension with splanchnic vasodilatation was first associated with hyperdynamic circulation that characterized by increased cardiac output, decreased arterial pressure, peripheral resistance and marked activation of endogenous vasoactive systems that further aggravated the hyperdynamic circulation and cardiac strain $[1,2]$. Later, cirrhotic patients exhibited circulatory and cardiac dysfunctions predominantly governed by peripheral vasodilatation [2]

Cirrhotic cardiomyopathy has been observed in liver cirrhosis, it involves impaired cardiac contractility, systolic and diastolic dysfunction, and electrophysiological abnormalities without known cardiac diseases [3].

These cardio-vascular dysfunctions may affect the prognosis of cirrhosis and aggravate its course during invasive procedures such as surgery, insertion of a Transjugular Intrahepatic Porto-Systemic Shunts (TIPS), also, they are of great interest in prioritization of transplantation lists, during and post-transplant prognosis as liver transplantation has been shown to ameliorate the cardiac and circulatory disturbances $[4,5]$.
In certain situations, there is a challenge in clinical judgment to distinguish primary liver disease or heart failure especially in the presence of ascites, as both diseases may have inconclusive traditional testing or diagnostic uncertainty. Hepatic patients may have symptoms resembling chronic heart failure like fatigue, dyspnea that was not proportional to liver affection. Also, cardiac patients may have picture simulating liver disease e.g. jaundice, unapparent jugular venous distension, lower limb edema, elevated liver enzymes and transudate ascites with SAAG > 1.1. Therefore, different investigative modalities may be needed to diagnose the etiology and assess cardiac function in liver cirrhosis such as echocardiology, hepatic venous pressure gradient and isotope ventriculography. However, these tests are more invasive,

${ }^{*}$ Corresponding author: Elham Ahmed Hassan, Department of Tropical Medicine and Gastroenterology, Faculty of Medicine, Assiut University, Assiut, Egypt, E-mail: mam_elham75@yahoo.com

Received July 03, 2013; Accepted August 17, 2013; Published August 26, 2013 Citation: Hassan EA,El-Rehim ASDA, Sayed ZEAA, Abdelhafez HA, Abdelhameed MR (2013) N-Terminal Pro-Brain Natriuretic Peptide: Prognostic Potential in End Stage Liver Cirrhosis in a Cohort Free of Heart Failure; an Egyptian Insight. J Liver 2: 125. doi:10.4172/2167-0889.1000125

Copyright: (c) 2013 Hassan EA, et al. This is an open-access article distributed under the terms of the Creative Commons Attribution License, which permits unrestricted use, distribution, and reproduction in any medium, provided the original author and source are credited. 
expensive and highly technical that may not be available and have their share of potential complications.

Natriuretic Peptide (NP) system has emerged as one of the most important hormonal systems in the control of cardiovascular homeostasis and function via coordinated central and peripheral actions [6]. NPs promote natriuresis and diuresis, act as vasodilators and antagonise the vasoconstrictor effects of the renin-angiotensinaldosterone system [7]. Ventricles become an important source of NPs, particularly Brain-Type Natriuretic Peptide (BNP) in response to myocardial ischaemia and stretch by volume and pressure overload [6]. N-terminal-proBNP (NT-proBNP) resulting from cleavage of ProBNP (a precursor of BNP) is more stable with longer half-life, it has been shown to be superior in predicting morbidity and mortality or hospitalization for chronic heart failure and an even better indicator of early cardiac dysfunction than BNP $[8,9]$.

Previous studies revealed increased NP concentrations in patients with cirrhosis suggesting cardiac dysfunction $[8,10,11]$. However, few studies had demonstrated NP significance in prognosis of liver cirrhosis. So, lack studies in our locality encouraged us to do this work. Therefore, the aims of our study were to measure serum and ascitic NTproBNP levels in cirrhotic and cardiac Egyptian patients to diagnose a cut-off value for exclusion of heart failure (especially in the presence of ascites), to assess if liver cirrhosis per se may contribute in NT-proBNP elevation and to assess the contribution of these levels as predictors of mortality in liver cirrhosis.

\section{Patients and Methods}

\section{Study design}

This was a single-central prospective cohort study with 1 year of follow-up carried out at Assiut University Hospital (AUH), Egypt, from October 2011 to October 2012. The study was approved by the Ethics Committee of AUH and informed consent was obtained from all the participants before enrollment.

\section{Study population}

A total of 80 patients (50 with liver cirrhosis and 30 with heart failure) were enrolled in this study. Cirrhotic patients had diagnostic criteria of liver cirrhosis (LC) by clinical, biochemical and ultrasonographic findings. The cause of liver dysfunction was hepatitis C. Severity of liver cirrhosis was assessed according to ChildPugh classification and MELD scores. Diagnosis of heart failure was based on established clinical findings and imaging signs (chest X-ray, electrocardiography and echocardiography). Twenty four healthy individuals had no hepatic or cardiovascular diseases, they matched for sex and age with patients and they were served as controls. These patients were selected from outpatient clinics and inpatient wards of the departments of Tropical Medicine and Internal Medicine, Assiut University Hospital (AUH) and controls were selected randomly from outpatient clinic and relatives of the patients admitted to our department. All cirrhotic patients and controls had normal cardiac physical examination, absent signs of cardiomegaly on chest X-ray and fairly normal electrocardiography (ECG) findings. Exclusion criteria included

\section{- Patients with renal, pulmonary disease, thyrotoxicosis, sepsis}

- Patients with non-cardiac cause of heart failure (Heart failure that is not caused by a form of heart disease e.g. heart failure caused by anemia, decompensated cor pulmonale, renal failure)
- Cirrhotic patients with cardiac diseases, renal impairment and obesity were excluded.

At study entry, a thorough medical history was taken and measurement of NT-pro-BNP and other biochemical parameters were undergone. At the same time, echocardiography was performed. All cirrhotic patients were followed up prospectively for one year with emphasis on their survival status. Surveillance was made by direct contact or telephone with patients or relatives and observation of medical records.

\section{Method}

Venous blood and ascitic (if available) samples; 3-5 $\mathrm{ml}$ for each, were obtained from the stable participant at the same time. Samples were collected and centrifuged immediately. Serum and ascitic samples were frozen at $-80^{\circ} \mathrm{C}$ until assayed. NT-proBNP levels were measured by enzyme immunoassay (using commercially available kits, purchased from Biomedica - Medizinprodukte GmbH \& Co kG, Wein, Austria) in accordance with the protocol of the manufacturer.

\section{Statistical Analysis}

All statistical analyses were conducted using SPSS for windows version 17 (SPSS Inc., Chicago, IL. USA). Continuous data were expressed as means \pm standard deviation (SD) or median and compared using Student's and ANOVA or Mann-Whitney U and Kruskal-Wallis tests for normally or abnormally distributed data respectively. Categorical variables were expressed as percentage and compared using chi-square $(\chi 2)$ test. NT-proBNP values and severity of liver cirrhosis were correlated by means of Spearman correlation. Survival curve for cirrhotic patients was generated by means of KaplanMeier estimates and differences in survival were compared by the logrank test. Multiple regression analysis was used to study the influence of independent variables on 1-year mortality. For all analyses, $\mathrm{P}$ value $<$ 0.05 was considered statistically significant.

\section{Results}

\section{Characteristics of the study population}

The baseline demographic and biochemical characteristics of the study population were summarized in Table 1 , where the study compromised 80 adult patients. Of these, 50 patients with liver cirrhosis were 14 females and 36 males with a mean age of $58 \pm 5.6$ years and 30 patients with heart failure were 8 females and 22 males with a mean age of $54.9 \pm 13.4$ years. While, control group formed of 6 females and 18 males with a mean age of $58 \pm 6.6$ years. There were no significant differences between studied groups as regard demographic data and between patients (LC, heart failure) regarding liver and renal functions.

There were 11 deaths within 1-year of follow up (one was Child B and 10 were Child C). The median serum and ascitic NT-proBNP levels in deceased patients were higher than survivors $(964.5$ and $292.6 \mathrm{pg} / \mathrm{ml}$ versus 268.6 and $223.3 \mathrm{pg} / \mathrm{ml}$ with $p<0.001$ and $p>0.05$ respectively).

\section{Assessment of NT-pro BNP levels and its relation to severity of liver cirrhosis}

Serum and ascitic NT-proBNP values in heart failure group were significantly higher than liver cirrhosis (LC) group $(p<0.001$ for both) (Figure 1). As shown in our study, the lowest serum and ascitic NT-proBNP levels in patients with cardiac ascites was 1130 and 982 $\mathrm{pg} / \mathrm{ml}$, whereas the highest serum and ascitic NT-proBNP levels in patients with cirrhosis was 1494.4 and $1175.8 \mathrm{pg} / \mathrm{ml}$ respectively. Therefore using values greater than $1000 \mathrm{pg} / \mathrm{ml}$, serum and ascitic NT- 


\begin{tabular}{|c|c|c|c|}
\hline & $\begin{array}{c}\text { Cirrhosis } \\
(n=50)\end{array}$ & $\begin{array}{l}\text { Heart failure } \\
\quad(n=30)\end{array}$ & $\begin{array}{l}\text { Control } \\
(n=24)\end{array}$ \\
\hline Age & $\begin{array}{c}(50-76) \\
58 \pm 5.6\end{array}$ & $\begin{array}{c}(45-68) \\
54.9 \pm 13.4\end{array}$ & $\begin{array}{c}(50-76) \\
58 \pm 6.6\end{array}$ \\
\hline $\begin{array}{l}\text { Sex } \\
\text { Male (\%) } \\
\text { Female (\%) }\end{array}$ & $\begin{array}{l}36(72) \\
14(28)\end{array}$ & $\begin{array}{c}22(73.3) \\
8(26.7)\end{array}$ & $\begin{array}{l}18(75) \\
6(25)\end{array}$ \\
\hline Child-Pugh score & $11.7 \pm 1.3$ & - & - \\
\hline $\begin{array}{l}\text { Child-Pugh class } \\
\text { Child (A) } \\
\text { Child (B) } \\
\text { Child (C) }\end{array}$ & $\begin{array}{l}10(20 \%) \\
12(24 \%) \\
28(56 \%)\end{array}$ & - & - \\
\hline MELD score & $17.5 \pm 6.4$ & - & - \\
\hline Serum creatinine (mg/dl) & $1.6 \pm 1$ & $1.9 \pm 1.4$ & $1 \pm 0.4$ \\
\hline Serum bilirubin (mg/dl) & $2.9 \pm 2$ & $2.2 \pm 1.1$ & $0.6 \pm 0.2$ \\
\hline Serum total protein & $65.5 \pm 6.7$ & $69.6 \pm 5.5$ & $78.9 \pm 5.3$ \\
\hline Serum albumin & $19.5 \pm 5.2$ & $21.1 \pm 4.6$ & $42.6 \pm 2.2$ \\
\hline AST & $60.3 \pm 56.7$ & $54 \pm 21$ & $24.8 \pm 8.6$ \\
\hline ALT & $36 \pm 28.2$ & $30.3 \pm 15.6$ & $22.2 \pm 8.9$ \\
\hline Prothrombin time (sec) & $19.7 \pm 4.2$ & $18.4 \pm 2.2$ & $13 \pm 1.1$ \\
\hline INR & $1.7 \pm 0.4$ & $1.6 \pm 0.2$ & $1.1 \pm 0.1$ \\
\hline Ascitic total protein $(\mathrm{g} / \mathrm{dl})^{*}$ & $1.2 \pm 0.2$ & $1.5 \pm 0.9$ & - \\
\hline $\begin{array}{l}\text { Serum TN-proBNP }(\mathrm{pg} / \mathrm{ml}) \\
\text { Mean } \\
\text { Median } \\
\text { Range }\end{array}$ & $\begin{array}{c}415.3 \pm 383.4 \\
239.4 \\
62-1494.4\end{array}$ & $\begin{array}{c}9168.8 \pm 5101.7 \\
10596.6 \\
1130-14351.5\end{array}$ & $\begin{array}{c}57.1 \pm 18.9 \\
61 \\
28-86\end{array}$ \\
\hline $\begin{array}{l}\text { Ascitic TN-proBNP }(\mathrm{pg} / \mathrm{ml}) \\
\text { Mean } \\
\text { Median } \\
\text { Range }\end{array}$ & $\begin{array}{c}382 \pm 330.3 \\
267 \\
8.5-1175.8\end{array}$ & $\begin{array}{c}8088.6 \pm 4131.6 \\
9771 \\
982.1-12781.7\end{array}$ & \\
\hline
\end{tabular}

'SAAG in both groups were $>1.1$

Table 1: Demographic and biochemical characteristics of the study population.

proBNP had sensitivity of $100 \%$ and $93.3 \%$; specificity of $97.8 \%$ and 92.5\%, positive predictive value was $93.8 \%$ and $90.3 \%$ respectively in predicting heart failure and excluding primary liver disease.

Serum NT-proBNP level was higher in patients with liver cirrhosis compared to age and sex matched healthy control $(p<0.001)$ (Figure 2). Although cirrhotic patients with Child $C$ had higher serum and ascitic NT-proBNP levels than those with Child A and B, these differences were not significant ( $p>0.05$ for both) (Figure 3).

In addition, elevation of serum and ascitic NT-proBNP levels was positively correlated with the severity of liver cirrhosis based on ChildPugh and MELD scores ( $p=0.05, p<0.001$ respectively) (Table 2). Figure 4 showed significant positive correlation between serum and ascitic NT-proBNP levels in both cardiac and cirrhotic cases $(\mathrm{r}=0.744$, $p<0.001$ and $\mathrm{r}=0.897, p<0.001$ respectively).

\section{Determination of the survival analysis}

Figure 5 showed Kaplan-Meier survival estimates of cirrhotic patients stratified by median of serum and ascitic NT-proBNP levels predicting increased 1-year mortality in patients with higher levels compared with those with lower levels $(p=0.003$ and $p>0.05$ respectively).

\section{Assessment of NT-proBNP as a risk factor for 1-year mortality}

To choose the factors that can independently predict the survival in cirrhotic group, multiple regression analysis was applied; using the variables from univariate analysis that had to be significantly $(P<0.05)$ associated with 1-year mortality, where, increasing serum and ascitic NT-proBNP levels were independent risk factors for mortality $(p=0.004$ and 0.05 respectively) in addition to other conventional factors such as hypoalbuminemia and high serum bilirubin and creatinine levels and severity of liver cirrhosis (Table 3).

\section{Discussion}

In this cohort study both serum and ascitic NT-proBNP levels were measured in advanced cirrhotic and cardiac Egyptian patients to diagnose a cut-off value for exclusion of heart failure and to assess the contribution of these levels as predictors of mortality in liver cirrhosis.

Cardiac patients could be misdiagnosed when they presented with a picture simulating liver disease e.g. hepatomegaly, transudate ascites with SAAG > 1.1, etc. They could even be missed with a non conclusive cardiac function assessment, especially in elderly with normal left ventricular ejection fraction or when invasive methods were not available, expensive or requiring specialized clinical staff.

In the present study, serum NT-proBNP level was higher in patients with heart failure compared to that with liver cirrhosis. This results matched with several studies $[12,13]$. Our study was in agreement with Sheer et al. [12] where serum and ascitic fluid NT-proBNP concentrations were found to be closely related and had similar

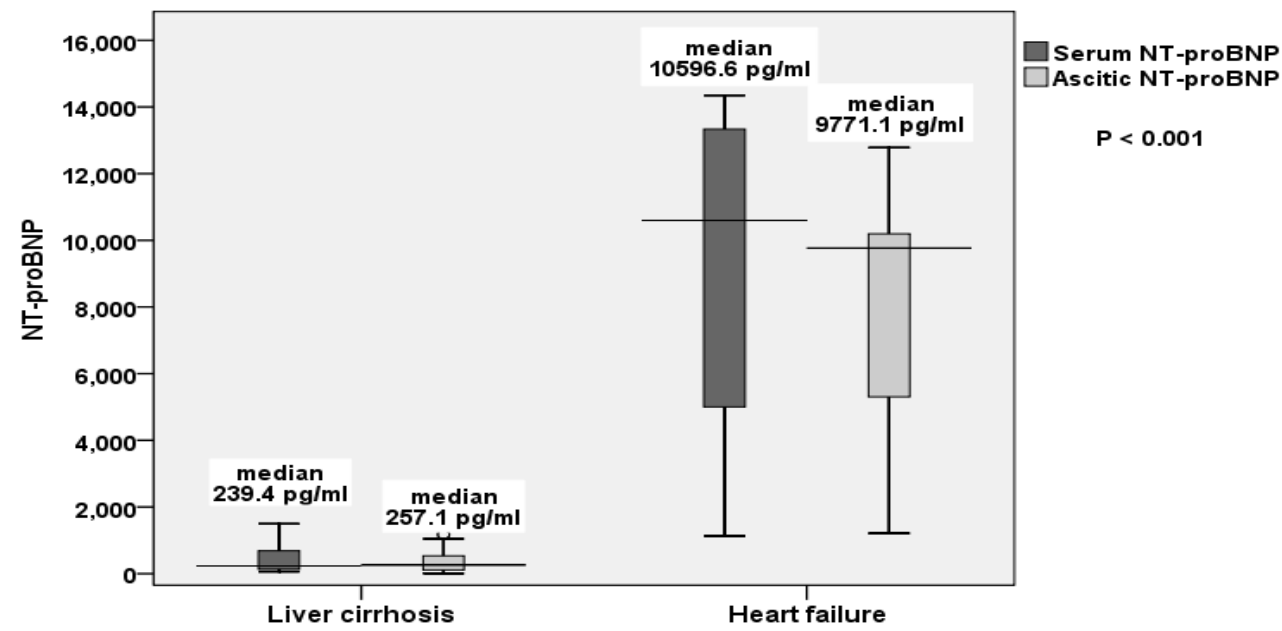

Figure 1: Serum and ascitic NT-proBNP levels in heart failure group were significantly higher than that in liver cirrhosis group ( $<0.001$ for both). 


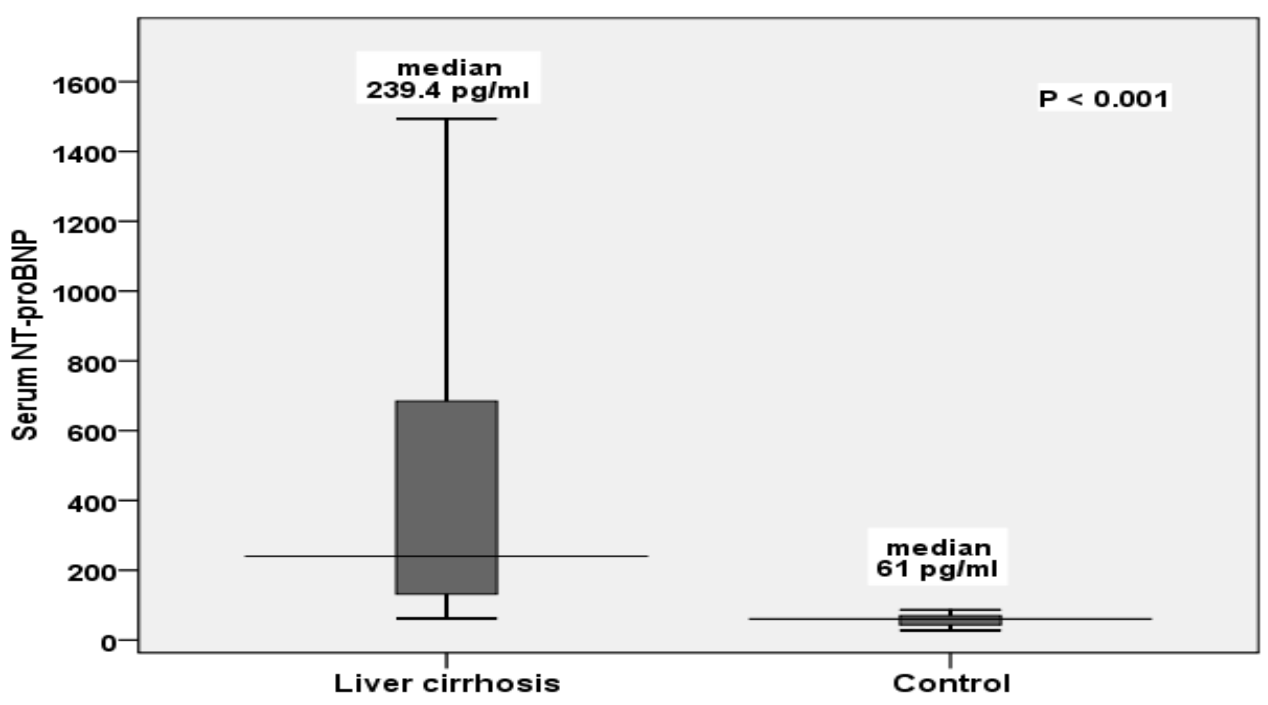

Figure 2: Serum NT-proBNP level in liver cirrhosis group was significantly higher than that in control group $(P<0.001)$.

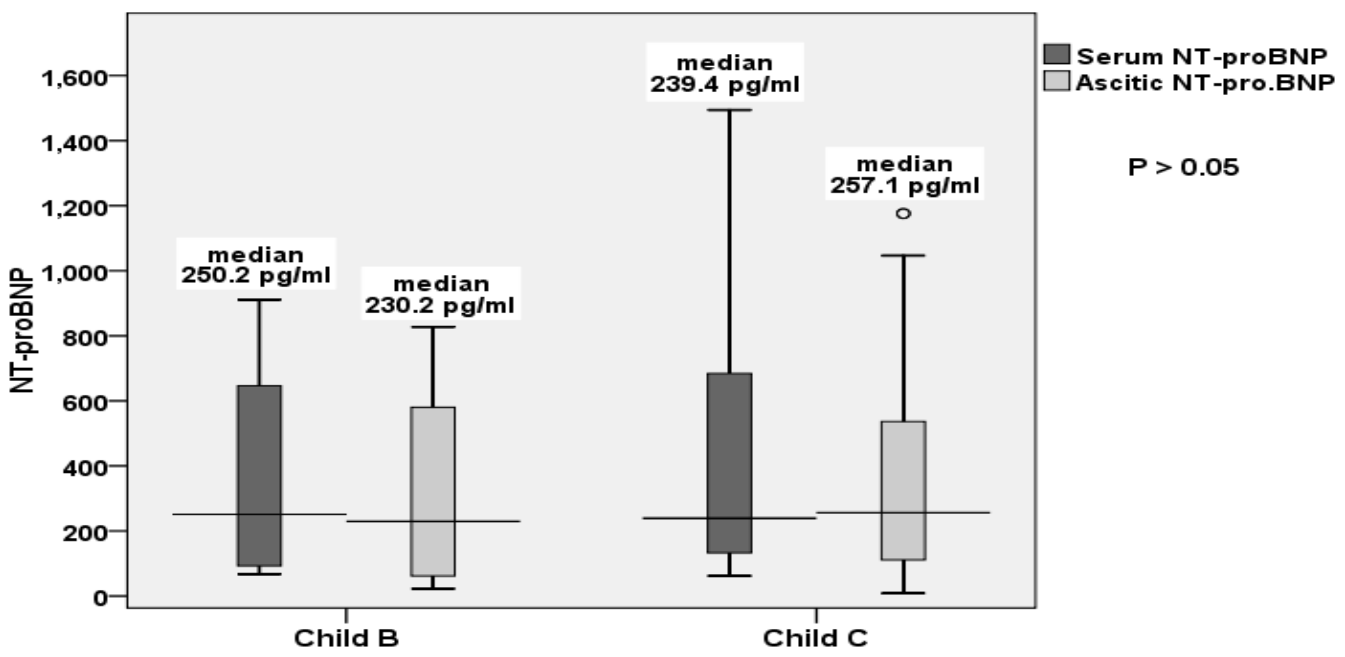

Figure 3: Serum and ascitic NT-proBNP levels in Child (C) group were higher than that in Child (B) group but these differences were not significant $(P=0.07$ and 0.1 respectively).

\begin{tabular}{|c|c|c|c|c|}
\hline & \multicolumn{2}{|c|}{ Serum NT-proBNP } & \multicolumn{2}{|c|}{ Ascitic NT-proBNP } \\
\cline { 2 - 5 } & Correlation Coefficient & $\boldsymbol{P}$ & Correlation Coefficient & $\boldsymbol{P}$ \\
\hline Child-Pugh score & 0.317 & 0.002 & 0.380 & 0.05 \\
\hline MELD score & 0.615 & $<0.001$ & 0.350 & 0.001 \\
\hline Serum albumin & -0.427 & 0.02 & -0.405 & $<0.001$ \\
\hline Prothrombin time & 0.463 & $<0.001$ & 0.300 & 0.01 \\
\hline Serum bilirubin & 0.637 & $<0.001$ & 0.035 & 0.8 \\
\hline
\end{tabular}

Table 2: Correlation between serum and ascitic NT-proBNP levels and severity of liver cirrhosis.

diagnostic accuracy. Hence, ascitic fluid as well as serum NT-proBNP concentrations were useful in the differential diagnosis of cardiac and non-cardiac origins of ascites.

Our results were in a concordance with previous studies $[12,14]$ that serum and ascitic fluid NT-proBNP levels with cut-off value greater than $1000 \mathrm{pg} / \mathrm{ml}$ was sensitive and specific in distinguishing patients with heart failure from those with concurrent extracellular volume overload in decompensated liver cirrhosis. Bursi et al. this peptide is an effective biomarker in heart failure diagnosis and risk stratification, independent of ejection fraction [15].

We also found that both serum and ascitic NT-proBNP levels were elevated in cirrhotic patient but not as high as in heart failure. This was attributed to the direct relation of elevated peptide to diastolic dysfunction and central hypervolemia in patients with advanced cirrhosis and large ascites $[3,15,16]$. In addition, this significant raising may be explained by their correlation with ventricular wall stress [17]. 

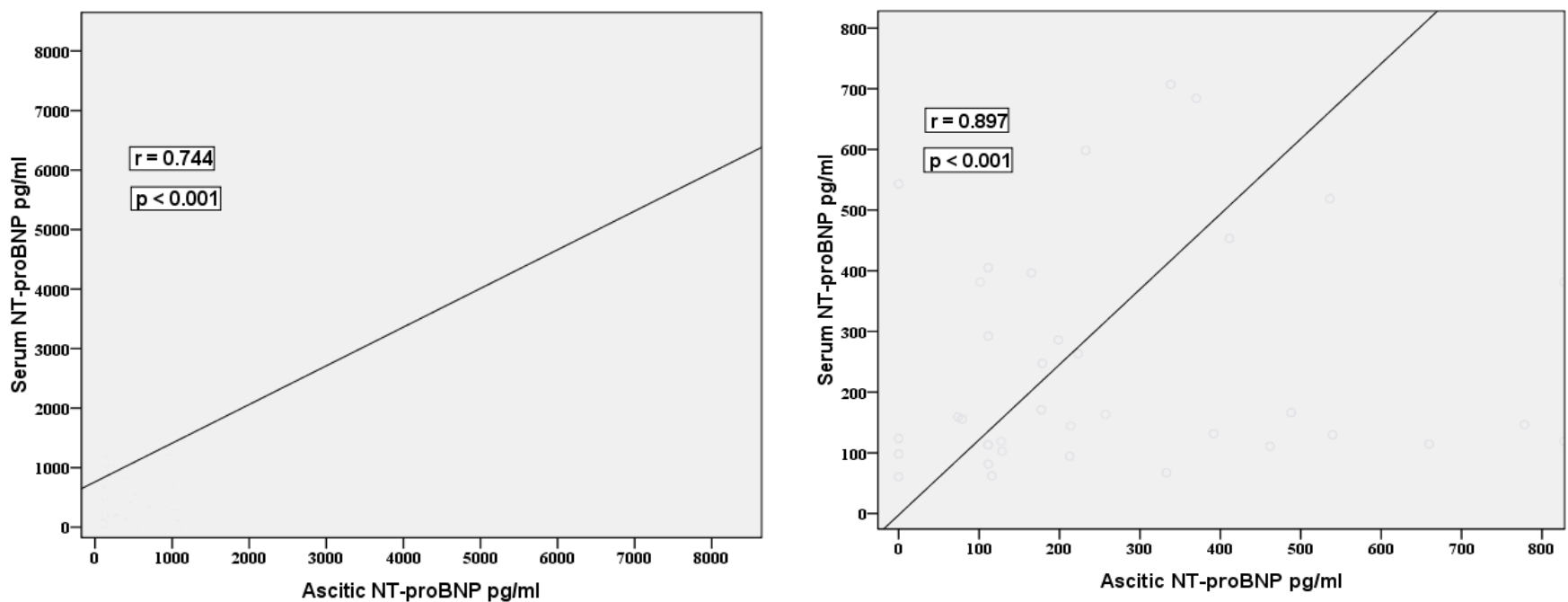

A

$\mathrm{B}$

Figure 4: Correlation between serum and ascitic NT-proBNP levels in cases with A) heart failure, B) liver cirrhosis.
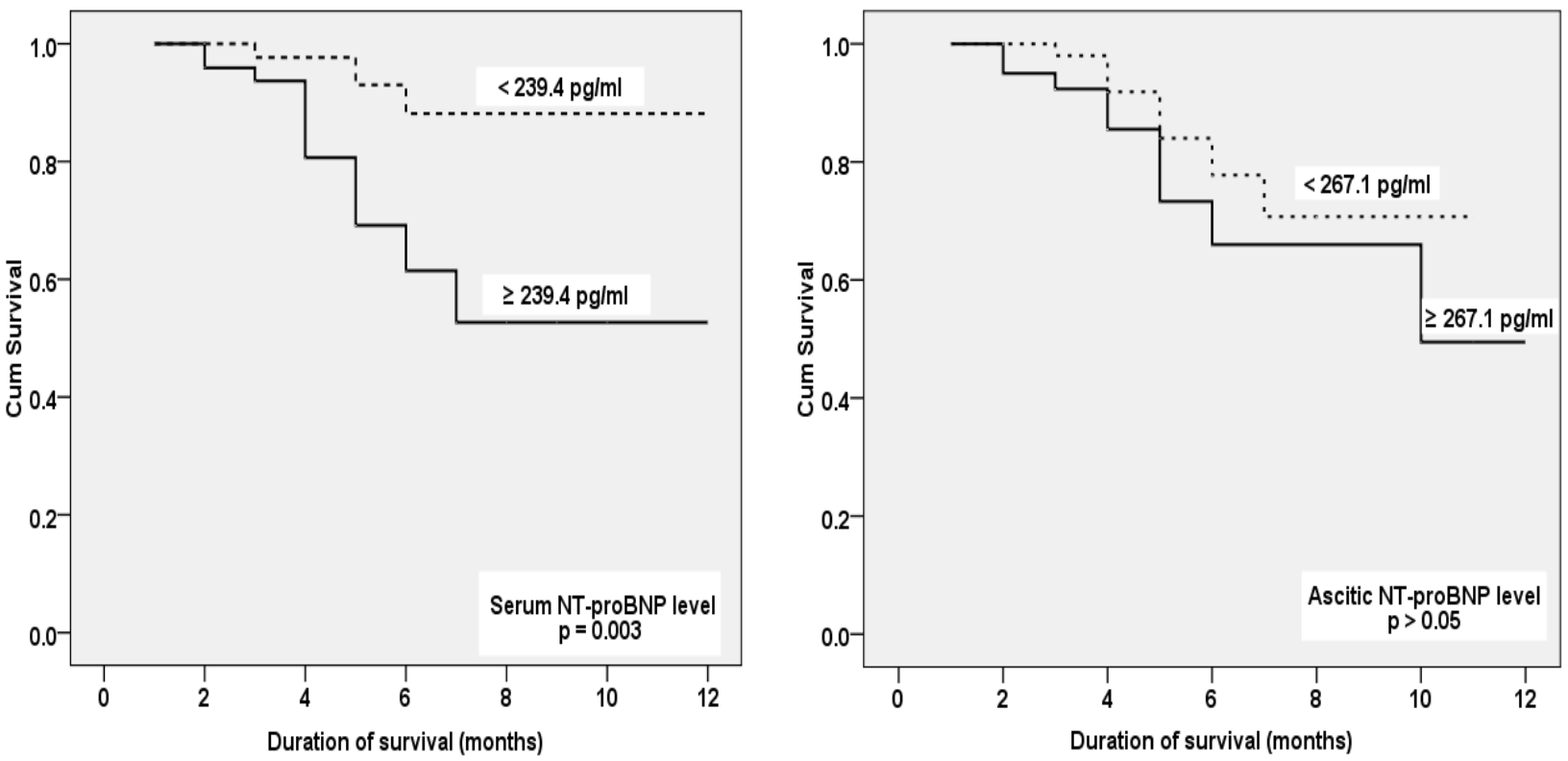

Figure 5: Kaplan-Meier survival curves predicting increased mortality with: higher serum and ascitic NT-proBNP levels in patients with liver cirrhosis $(p=0.003$ and $\mathrm{p}=0.09$ respectively).

In the present study, our results were comparable to several studies $[8,10,11]$, where NT-proBNP levels were raised in cirrhotic patients in comparison to non-cirrhotic, non-cardiac age matched healthy controls. In addition, we noticed that these levels were positively correlated with Child-Pugh and MELD scores as demonstrated in the reported studies $[11,17,18]$.

NT-proBNP elevation in liver cirrhosis may be multifactorial; as the possible cardiovascular changes in cirrhotic patients varied from subtle cardiac dysfunction to severe cirrhotic cardiomyopathy. These were accompanied by hyperdynamic circulation, increased cardiac output and plasma volume [19]. However, previous studies had shown that increased ventricular generation of these peptides indicating the presence of cardiac dysfunction, rather than being caused by the hyperdynamic circulatory changes $[8,11,20]$. Also, it may be partially explained by the physiological increased NT-proBNP levels with increasing age of the studied patients [21].

Moreover, the increased intravascular volume in cirrhosis may be attributed to porto-pulmonary hypertension [22] that leads to 


\begin{tabular}{|c|c|c|}
\hline Variable & Hazard ratio $\mathbf{( 9 5 \%} \mathbf{~ C l )}$ & P value \\
\hline Age & $1.02(0.98-1.06)$ & 0.6 \\
\hline Serum albumin & $0.92(0.86-0.98)$ & 0.007 \\
\hline Serum bilirubin & $1.17(1.07-1.28)$ & 0.001 \\
\hline Prothrombin time & $0.91(0.81-1.01)$ & 0.09 \\
\hline Serum creatinine & $1.01(1.002-1.011)$ & 0.002 \\
\hline Child-Pugh score & $1.04(0.81-1.33)$ & 0.02 \\
\hline MELD score & $0.96(0.88-1.09)$ & 0.05 \\
\hline Serum NT -proBNP & $1.001(1-1.002)$ & 0.004 \\
\hline Ascitic NT -proBNP & $1.001(1.001-1.002)$ & 0.05 \\
\hline
\end{tabular}

Table 3: Multiple regression analysis of risk factors affected 1-year mortality in liver cirrhosis group.

ventricular remodeling and myocyte stretch, which consequently elevates NT-proBNP levels in both serum and ascites [23].

Increased levels of NT-proBNP in the majority of our cirrhotic population having hepatitis $\mathrm{C}$ infection with no history of previous cardiac disease may declare that they suffered from cardiac abnormalities, structural or functional changes. This was supported by other authors reported that these changes correlated with increased blood levels of NT-proBNP $[11,24,25]$.

Our data showed that higher serum and ascitic NT-proBNP levels were independent predictors of 1-year mortality in cirrhotic patients with normal cardiac assessment (no heart failure). These results agreed with Wang et al. [26] who reported that elevated levels of NT-proBNP had been regarded as a risk factor for death. This predictive power of NTproBNP for mortality in cirrhotic patients may be explained partially by its relation with extracellular volume expansion (congestive state) apart from cardiac morphology and function [27]. Also, increased BNP level in cirrhotic patients may have a role in fibrosis. Tsuruda et al. [28] explained that besides cardiac myocytes, fibroblasts secrete BNP which leads to hepatic fibrosis and vascular remodeling through induction of matrix metalloproteinases.

Our study results recommend the estimation of either serum or ascetic NT-proBNP preoperative or intraoperative to predict the cardiac complications outcome of Liver Transplantation (LT) postoperatively. Thus, reduce the need for other more expensive and invasive diagnostic tests. In spite several studies recommended preoperative cardiac function evaluation in cirrhotic patients before (LT) in order to predict cardiac dysfunctions, $10 \%$ of hepatic patients with normal cardiac function suffered major complications in the posttransplant phase [29-31].

Our limitation was small sample sized study, and needs to be supported by further large number prospective studies to evaluate its association with cardiac changes especially before OLT to improve postoperative outcomes.

\section{Conclusion}

In conclusion, NT-pro BNP could be a powerful initial noninvasive diagnostic tool to be used in clinical practice for exclusion of cardiac dysfunction in decompensated cirrhotic patients as a part of the workup to overcome missed or misdiagnosis. End stage liver cirrhosis per se may contribute to NT-proBNP elevation which contributes as incremental information for the prediction of 1-year mortality in end stage liver cirrhosis.

\section{References}

1. Kowalski HJ, Abelmann WH (1953) The cardiac output at rest in Laennec's cirrhosis. J Clin Invest 32: 1025-1033.
2. M?ller S, Henriksen JH (2005) The systemic circulation in cirrhosis. In: Gines P Arroyo V, Rodes J, Schrier RW, editors. Ascites and renal dysfunction in liver disease. Malden: Blackwell; 139-155.

3. Møller S, Henriksen JH (2010) Cirrhotic cardiomyopathy. J Hepatol 53: 179190

4. Rabie RN, Cazzaniga M, Salerno F, Wong F (2009) The use of E/A ratio as a predictor of outcome in cirrhotic patients treated with transjugular intrahepatic portosystemic shunt. Am J Gastroenterol 104: 2458-2466.

5. Torregrosa M, Aguadé S, Dos L, Segura R, Gónzalez A, et al. (2005) Cardiac alterations in cirrhosis: reversibility after liver transplantation. J Hepatol 42: 68 74.

6. Levin ER, Gardner DG, Samson WK (1998) Natriuretic peptides. N Engl J Med 339: 321-328.

7. Mukoyama M, Nakao K, Saito Y, Ogawa Y, Hosoda K, et al. (1990) Human brain natriuretic peptide, a novel cardiac hormone. Lancet 335: 801-802.

8. Henriksen JH, Gøtze JP, Fuglsang S, Christensen E, Bendtsen F, et al (2003) Increased circulating pro-brain natriuretic peptide (proBNP) and brain natriuretic peptide (BNP) in patients with cirrhosis: relation to cardiovascular dysfunction and severity of disease. Gut 52: 1511-1517.

9. Gøtze JP, Kastrup J (2001) Plasma pro-brain natriuretic peptides are strong biochemical markers in clinical cardiology. Scand J Clin Lab Invest Suppl 234 $47-51$.

10. Woo JJ, Koh YY, Kim HJ, Chung JW, Chang KS, et al. (2008) N-terminal pro B-type natriuretic peptide and the evaluation of cardiac dysfunction and severity of disease in cirrhotic patients. Yonsei Med J 49: 625-631.

11. Eldeeb M, Fouda RMFR, Hammady MMR, Rashed L (2012) Echocardiographic Evaluation of Cardiac Structural and Functional Changes in Hepatitis C Positive Non-Alcoholic Liver Cirrhosis Patients and Their Plasma NT-ProBNP Levels Life Science Journal 9: 786-792.

12. Sheer TA, Joo E, Runyon BA (2010) Usefulness of serum N-terminal-ProBNP in distinguishing ascites due to cirrhosis from ascites due to heart failure. J Clin Gastroenterol 44: e23-26.

13. Januzzi JL Jr, Camargo CA, Anwaruddin S, Baggish AL, Chen AA, et al. (2005) The N-terminal Pro-BNP investigation of dyspnea in the emergency department (PRIDE) study. Am J Cardiol 95: 948-954.

14. Zoccali C, Mallamaci F, Benedetto FA, Tripepi G, Parlongo S, et al. (2001) Cardiac natriuretic peptides are related to left ventricular mass and function and predict mortality in dialysis patients. J Am Soc Nephrol 12: 1508-1515.

15. Bursi F, Weston SA, Redfield MM, Jacobsen SJ, Pakhomov S, et al. (2006) Systolic and diastolic heart failure in the community. JAMA 296: 2209-2216.

16. Maisel AS, McCord J, Nowak RM, et al. (2003) Breathing Not Properly Multinational Study Investigators. Bedside B-type natriuretic peptide in the emergency diagnosis of heart failure with reduced or preserved ejection fraction. Results from the Breathing Not Properly Multinational Study. J Am Col Cardiol 41:2010-2017

17. Padillo J, Rioja $P$, Muñoz-Villanueva MC, Vallejo JA, Ciria $R$, et al. (2010) BNP as marker of heart dysfunction in patients with liver cirrhosis. Eur J Gastroenterol Hepatol 22: 1331-1336

18. Huh IY, Kim YK, Shin WJ, Park SE, Bang JY (2012) Increased B-Type Natriuretic Peptide during Liver Transplantation: Relationship to Invasively Measured Hemodynamic Parameters. Transplantation Proceedings 44, 13181322.

19. Ruiz-del-Arbol L, Monescillo A, Arocena C, Valer P, Ginès P, et al. (2005) Circulatory function and hepatorenal syndrome in cirrhosis. Hepatology 42 439-447.

20. Møller S, Henriksen JH (2008) Cardiovascular complications of cirrhosis. Gut 57: 268-278

21. Galasko GI, Lahiri A, Barnes SC, Collinson P, Senior R (2005) What is the normal range for $\mathrm{N}$-terminal pro-brain natriuretic peptide? How well does this normal range screen for cardiovascular disease? Eur Heart J 26: 2269-2276.

22. Kim YK, Seong SH, Jun IG, Chin JH, Sang BH et al. (2011) Preoperative Echocardiographic Indices Associated With Elevated Brain Natriuretic Peptide in Liver Transplant Recipients. Transplantation Proceedings; 43, 1691-1695.

23. Jiménez W, Arroyo V (2003) Origins of cardiac dysfunction in cirrhosis. Gut 52: 1392-1394. 
Citation: Hassan EA,El-Rehim ASDA, Sayed ZEAA, Abdelhafez HA, Abdelhameed MR (2013) N-Terminal Pro-Brain Natriuretic Peptide: Prognostic Potential in End Stage Liver Cirrhosis in a Cohort Free of Heart Failure; an Egyptian Insight. J Liver 2: 125. doi:10.4172/2167-0889.1000125

Page 7 of 7

24. Matsumori A, Shimada T, Chapman NM, Tracy SM, Mason JW (2006) Myocarditis and heart failure associated with hepatitis $C$ virus infection. J Card Fail 12: 293-298

25. Matsumori A (2009) Global alert and response network for hepatitis C virusderived heart diseases: A call to action CVD. Prevention and Control; 4: 109118

26. Wang L, Geng J, Li J, Li T, Matsumori A, et al. (2011) The biomarker N-terminal pro-brain natriuretic peptide and liver diseases. Clin Invest Med 34: E30-37.

27. Pimenta J, Paulo C, Gomes A, Silva S, Rocha-Gonçalves F, et al. (2010) B-type natriuretic peptide is related to cardiac function and prognosis in hospitalized patients with decompensated cirrhosis. Liver Int 30: 1059-1066.

28. Tsuruda T, Boerrigter G, Huntley BK, Noser JA, Cataliotti A, et al. (2002)
Brain natriuretic Peptide is produced in cardiac fibroblasts and induces matrix metalloproteinases. Circ Res 91: 1127-1134.

29. Donovan CL, Marcovitz PA, Punch JD, Bach DS, Brown KA, et al. (1996) Twodimensional and dobutamine stress echocardiography in the preoperative assessment of patients with end-stage liver disease prior to orthotopic liver transplantation. Transplantation 61: 1180-1188.

30. Cazzaniga M, Salerno F, Pagnozzi G, Dionigi E, Visentin S, et al. (2007) Diastolic dysfunction is associated with poor survival in patients with cirrhosis with transjugular intrahepatic portosystemic shunt. Gut 56: 869-875.

31. Ratti L, Redaelli E, Guidi C, Rivera R, Wong F, et al. (2005) [Diastolic dysfunction in liver cirrhosis]. Gastroenterol Hepatol 28: 649-655. 